\title{
Yes and yes again: are standards of care which require two referrals for genital reconstructive surgery ethical?
}

W.P. Bouman ${ }^{\mathrm{a} *}$, C. Richards ${ }^{\mathrm{a}, \mathrm{b}}$, R.M. Addinall ${ }^{\mathrm{c}}$, I. Arango de Montis ${ }^{\mathrm{d}}$, J. Arcelus $^{\mathrm{a}}$,

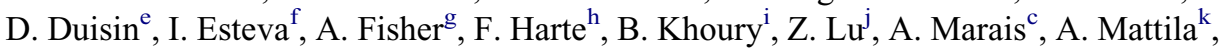
D. Nayarana Reddy ${ }^{1}$, T.O. Nieder ${ }^{\mathrm{m}}$, R. Robles Garcia ${ }^{\mathrm{d}}$, O.M. Rodrigues $\mathrm{Jr}^{\mathrm{n}}$, A. Roque Guerra ${ }^{\mathrm{o}}$, D. Tereshkevich ${ }^{\mathrm{p}}, \mathrm{G}$. T'Sjoen ${ }^{\mathrm{q}}$ and D. Wilson ${ }^{\mathrm{c}}$

${ }^{a}$ Nottingham Gender Clinic, Nottingham, United Kingdom; ${ }^{b}$ West London Mental Health Trust Gender Identity Clinic, London, United Kingdom; ${ }^{c}$ Groote Schuur Hospital, Department of Psychiatry and Mental Health, University of Cape Town, Cape Town, South Africa; ${ }^{d}$ Instituto Nacional de Psiquiatría Ramón de la Fuente Muñiz, Mexico City, Mexico; ${ }^{e}$ Cabinet for Transgender States, Clinic for Psychiatry Clinical Center of Serbia, Belgrade, Serbia, ${ }^{f}$ Andalusian Gender Team, Regional University Hospital, Malaga, Spain; ${ }^{g}$ Sexual Medicine and Andrology Unit, Interdepartmental Center for Gender Dysphoria Assistance, University of Florence, Florence, Italy; ${ }^{h}$ Gender Dysphoria Clinic, Melbourne, Australia $;{ }^{i}$ American University of Beirut Medical Center, Beirut, Lebanon, ${ }^{j}$ Shanghai Mental Health Center, Shanghai Jiao Tong University Medical School, Shanghai, China, ${ }^{k}$ General Hospital Psychiatry Unit, Tampere University Hospital,

Tampere, Finland; ${ }^{l}$ The Tamil Nadu Dr. MGR Medical University, Chennai, India, ${ }^{m}$ Institute and Outpatient Clinic for Sex Research and Forensic Psychiatry, University Medical Center HamburgEppendorf (UKE), Hamburg, Germany; ${ }^{n}$ Instituto Paulista de Sexualidade, Clinica de Psicologia em Sexualidade, São Paulo, Brazil; ${ }^{\circ}$ SOCUMES, Havana, Cuba; ${ }^{p}$ Human Health Institute, Astana, Kazakhstan; ${ }^{q}$ Center for Sexology and Gender Problems, University Hospital Ghent, Ghent, Belgium

(Received 30 June 2014; accepted 12 August 2014)

\begin{abstract}
The commonly used Standards of Care for people with gender dysphoria, including those of the World Professional Association for Transgender Health and The Royal College of Psychiatrists in the United Kingdom, as well as those standards used in many other countries, usually require that two signatures of approval from qualified mental health professionals be provided before genital reconstructive surgery (GRS) sometimes called sexual reassignment surgery or gender confirmation surgery - is undertaken. This is different from surgeries which are similarly irreversible and remove reproductive capacity carried out on cisgender people. This paper explores the transspecific issues from a standpoint of medical ethics and argues that, provided sufficient safeguards are in place, including assessment within a multidisciplinary team, a nuanced approach utilising a single signature may instead be appropriate.
\end{abstract}

Keywords: Standards of Care; gender dysphoria; trans-sexualism; transgender; genital reconstructive surgery; medical ethics

\section{Introduction}

The Harry Benjamin International Gender Dysphoria Association (now known as the World Professional Association of Transgender Health - WPATH) authored the first Standards of Care (SoC) for people with gender dysphoria with the express purpose of articulating professional consensus regarding the psychiatric, psychological, medical, and surgical management of gender dysphoria (Walker et al., 1985) and give specific

*Corresponding author. Email: walterbouman@doctors.org.uk 
"minimum" requirements as pre-requisites to hormone treatment and sex reassignment surgeries (SRS), including genital reconstructive surgery (GRS). The current version 7 recommends that one written opinion from a qualified mental health professional is required prior to starting hormone treatment and in order to undergo chest surgeries such as bilateral mastectomy and associated reconstruction for trans men $^{1}$ or augmentation mammoplasty for trans women ${ }^{2}$ (Coleman et al., 2012). In contrast, two referrals from qualified mental health professionals who have independently assessed the patient for eligibility and readiness are needed for genital surgeries such as hysterectomy, salpingooophorectomy, bilateral orchidectomy and genital reconstructive surgeries to form a neovagina or neophallus. These written opinions must also include a diagnosis of gender dysphoria (American Psychiatric Association, 2013) or trans-sexualism (World Health Organization [WHO], 1992). It is likely that this will, of course, include the analogous WHO diagnosis in the ICD-11 (International Classification of Diseases version 11) which may be called gender incongruence; however, we shall use the term gender dysphoria throughout this paper for ease of readability.

Currently, the WPATH SoC are the standards most commonly used by clinicians working in gender clinics, sometimes called gender identity clinic services, internationally. In European countries, such as Italy, the Netherlands, Germany and the United Kingdom where health care, including hormone treatment and GRS, is provided for all citizens free at point of delivery, national SoC have been developed, and are developing, which are often largely based on the principles underpinning the WPATH SoC. In the United Kingdom, for instance, contributors to WPATH's current SoC are members of the Royal College of Psychiatrists' Intercollegiate Committee on the United Kingdom SoC (Wylie et al., 2014). However, it is important to note that there is a key difference between privately and publicly funded health care. In the former, an absence of harm from treatment may be sufficient, provided the person accessing the intervention is making an informed decision. In the latter, there must be a demonstrable positive benefit of treatment for patients. This is because those paying for interventions for others (taxpayers) rightly expect their money to have been put towards some practical end and not merely be used to fulfil a desire on the part of the person seeking services. This creates a difference in practical application between the WPATH SoC and the United Kingdom SoC, as the United Kingdom SoC are generally used for publicly funded interventions.

The main aim for all of these $\mathrm{SoC}$ is to create a set of clinical guidelines which provide standards that secure a high quality care pathway for people with gender dysphoria, and consequently facilitate equality of access to assessment and treatment at gender clinics. However, before hormone and surgical treatment can commence, specific eligibility criteria must be met. It is difficult to define eligibility criteria in a truly objective manner (Bouman \& Richards, 2013) due to a dearth of level one evidence in the field (cf. Centre for Evidence Based Medicine [CEBM], 2013) and consequently determination of these criteria rests largely upon consensus between clinicians and non-clinicians developing SoC. It can be argued, however, that SoC establish and maintain medical and psychological "gatekeeping" through these eligibility criteria for people with gender dysphoria - meaning that the legitimate expression of the self-identified gender of the individual is not necessarily validated by $\mathrm{SoC}$ as written. Thus, the utilisation of $\mathrm{SoC}$ in determining whether a patient may receive treatment necessarily causes the individual's wishes to be balanced against the possibility that any intervention may cause harm to the patient.

In this paper, we will examine one particular aspect of both the WPATH and United Kingdom SoC which exemplifies such medical and psychological "gatekeeping" of services: that two written opinions from qualified mental health professionals are necessary 
for people with gender dysphoria to receive genital surgeries. The purpose of the second opinion is not discussed or clarified in any of the current SoC, despite the fact that obtaining the second opinion can cause delays in treatment, especially in sparsely populated areas, and may be seen by some as unduly invasive. Indeed, in the broader field of medicine aside from trans services, there are very few cases in which two opinions for physiological interventions are required and those which do mostly involve people who lack capacity to consent to treatment or people who are seen outside of a multidisciplinary team. For example, in the case of electroconvulsive treatment for a life threatening or severely debilitating psychiatric illness during which the patient is a minor or lacks capacity to consent to treatment (Cairns et al., 2005; Cresswell, Murphy, \& Hodge, 2012). Our intent, therefore, is to explicitly consider whether it is justified to require two written opinions for genital surgeries as a rule of general application, and especially to consider whether in cases where a patient is seen in a multidisciplinary/interdisciplinary team a single signature might be used instead.

\section{Gender dysphoria - a unique consideration}

The arguments concerning the considerations and approvals pertaining to what is today referred to as gender dysphoria or trans-sexualism, and may become known as gender incongruence in the forthcoming ICD-11, are based in a historical context in which gender dysphoria is one of the few psychiatric diagnoses for which the treatment does not involve reduction of the "symptoms" through addressing the psychology of the patient directly. Instead it concerns a transformation of the body to align with the patient's subjective experience of gender (Meyer-Bahlburg, 2010). Consequently, there has been a long-standing concern, which continues to this day in some quarters, that "psychiatric" patients may be having their delusions colluded with, or at least that an irreversible decision may be made which is later regretted. This stance is slowly changing with the realisation that trans people are no more likely that cisgender $^{3}$ people to suffer from mental illnesses aside from minority stress (Cole, O’Boyle, Emory, \& Meyer III, 1997; Colizzi, Costa, \& Todarello, 2014; Haraldsen \& Dahl, 2000; Hill, Rozanski, Carfagnini, \& Willoughby, 2005; Hoshiai et al., 2010; Kersting et al., 2003; Simon, Zsolt, Fogd, \& Czobor, 2011) and a consequent movement towards seeing trans people as mentally healthy individuals capable of making their own decisions about their bodies. As Drescher (2010) has noted:

\footnotetext{
It is not unthinkable that, in the future, gender variant people transitioning from one sex to another might be treated by medical specialists who, like obstetricians, use medical and surgical interventions to facilitate what society considers to be a normal life event. . . although the psychosocial context for evaluating gender variance is rapidly changing, today there is a practical concern that it might be difficult to convince most people that transition from one sex to another is as 'normal' as childbirth. (p. 453)
}

Consequently, we shall illustrate our consideration of trans people being treated as a special medico-legal case by considering the example of a trans woman who wishes to undergo an orchidectomy as part of genital surgery alongside a consideration of a man wishing to have an orchidectomy for a non-trans related matter. ${ }^{4}$ This procedure for a trans woman is one of the enumerated surgical procedures in the WPATH SoC and United Kingdom SoC requiring two referrals from qualified mental health professionals who have independently assessed a patient for eligibility and readiness. In addition, these SoC state that, in order to proceed with this type of genital surgery, patients must have received 
treatment consisting of cross-sex hormone therapy and at least one year of continuous living in a gender role that is congruent with one's identity. In contrast to the example given above, a cisgender male with chronic scrotal pain does not require any written psychiatric opinion for an orchidectomy nor does he have to be in pain or distress for a minimum of one year before surgery can take place (Keoghane \& Sullivan, 2010). Chronic scrotal pain - which has a greater prevalence than gender dysphoria (Leslie, Illing, Cranston, \& Guillebaud, 2007) - refers to an ill-understood complex of symptoms wherein patients often have no identifiable cause to explain their discomfort. Like gender dysphoria, chronic scrotal pain requires a clinical diagnosis based on symptoms which are often reported rather than immediately observed. Consequently, it is the surgeon in consultation with the patient who decides whether an orchidectomy is potentially beneficial. Similarly, a cisgender female with abnormal genital tract bleeding based in the uterus and found in the absence of demonstrable structural or organic pathology (known as dysfunctional uterine bleeding DUB, Edozien, 2006) does not require a psychiatric opinion for a hysterectomy and nor does she have to wait a minimum of one year to undergo surgery. As with chronic scrotal pain and gender dysphoria, DUB is not an acute medical condition (Phipps, 2007) which would invite a different set of ethical considerations based upon immediacy of need.

With regard to such chronic conditions then, the centre of clinical decision making in modern medicine is the moral imperative to respect the autonomy of the patient to make an informed decision regarding surgery (Beauchamp \& Childress, 2009; O'Neill, 2002). As there is general agreement that in ethical matters like cases should be treated alike (Veatch, 2003), treating trans people differently in respect of genital surgery must be supported by well-reasoned arguments.

\section{Reasons for medical/psychological "gatekeeping" regarding genital surgeries for gender dysphoria}

There are various arguments used to justify the necessity of two mental health professionals' written opinions as to the advisability of genital surgery. One such argument, often raised by clinicians, is that genital surgery involves removal of healthy tissue. Such surgical intervention can thus only be endorsed if there is sufficient confidence that the intervention is in the best interest of the patient, and hence a robust assessment system needs to be in place (Barrett, 2007; Ettner, Monstrey, \& Eyler, 2007). In order to be consistent, however, this condition ought to apply in all procedures which require the removal of healthy tissue, whether concerning gender dysphoria or otherwise. The removal of healthy tissue takes place in the aforementioned patients with chronic scrotal pain and DUB, without such an assessment system requiring two independent professional opinions. Indeed, a trans woman who seeks GRS and has been living continuously in her desired female gender role for a minimum of one year, and more realistically two, has had a significant amount of time to reflect about the benefits and risks of the surgery. Furthermore, as part of the ongoing support of the trans person at a gender clinic, the matter will have been brought up on several occasions by supporting professionals in the multidisciplinary/interdisciplinary team prior to the final evaluation. There is also a significant body of academic evidence suggesting that such genital surgeries improve the overall quality of life of carefully evaluated trans-sexual people who have had a consistent desire for such surgeries and who are not sexually motivated (De Cuypere et al., 2005; Gijs \& Brewaeys, 2007; Gooren, 2011; Klein \& Gorzalka, 2009; Murad et al., 2010; NHS Audit, Information \& Analysis Unit, 2008; Smith, Van Goozen, Kuiper, \& Cohen-Kettenis, 2005). 


\section{Irreversibility}

A further argument which follows from that pertaining to the loss of healthy tissue above, is that of the number of signatures required to allow other irreversible elective surgeries such as live kidney donation, and cosmetic facial, breast and genital surgery, for example. In such cases (when not related to gender dysphoria), either a single or no psychiatric or psychological opinion is required, often at the discretion of the operating surgeon. What then differentiates trans people from their cisgender counterparts in this regard? One argument often made is that the two-signature system limits reversion to the birth assigned gender role after gender-related surgeries as reversion can have catastrophic psychological sequelae. Indeed, around $2 \%-3 \%$ of trans people who have undergone genital surgery regret $i^{5}$ and revert to their assigned gender role (Landén, Walinder, Hambert, \& Lundström, 1998; Lawrence, 2003; Michel, Ansseau, Legros, Pitchot, \& Mormont, 2002; Nieder et al., 2013), although this is lower in areas which have stringent requirements before surgery. Whether this is an acceptable margin for such a complex procedure, what causes those reversions, and whether two signatures from within a multidisciplinary/interdisciplinary team avert more reversions are the pertinent points here. The question remains the balance which must be struck between draconian paternalism and catastrophic outcomes at the taxpayers' expense. As things stand, genital surgery improves the quality of life for most trans-sexual people (Murad et al., 2010) and it is consequently hard to imagine any other major life decision, such as whether to marry, whether to have children, whether to make a particular career choice and the like - which would yield such an overwhelmingly positive outcome (Lev, 2009). It is not clear, however, whether it is the two-signature system which is material to that excellent outcome, or whether it is the process of decision-making, perhaps living in role for a certain time, for example, which is integral to it.

\section{Loss of fertility}

A special case of irreversible surgeries might be that of such surgeries which carry with them an attendant loss of fertility, such as orchidectomy and hysterectomy (whether for trans reasons or otherwise). It is argued by some clinicians that in such cases, stringent selection criteria applied through two independent professional opinions reduces the number of regrets about fertility loss through the necessity of having fully considered the implications of the decision. Indeed, this might seem a sensible precaution as in cases of hysterectomy unrelated to gender dysphoria, approximately $3 \%$ of cisgender ${ }^{6}$ females regret hysterectomy and more than a quarter of these females showed some regret regarding the loss of fertility (Farquhar, Harvey, Yu, Sadler, \& Stewart, 2006). The complexity arises, however, as fertility loss is not necessarily absolute, since the advent of modern technologies which include sperm and egg retrieval and storage (Di Santo, Tarozzi, Nadalini, \& Borini, 2012; Loutradi et al., 2008). Furthermore, the argument for two signatures of approval for removal of reproductive capacity is, of course, equally applicable in cases involving removal of reproductive capacity for other difficulties of an apparently non-physiological aetiology - as in the cisgender male patient with chronic scrotal pain and cisgender female patient with DUB seen above. If we dismiss the notion that these procedures should also have a two-signature approval process, we return to the consideration of a one signature process applied fairly universally to both trans and non-trans health care. Consequently, a nuanced approach would seem warranted in these cases, perhaps taking into account the likelihood of a live birth from any cryopreservation methods, 
the age of the patient, whether the patient has children already and do not wish to have any more, etc. (Richards \& Seal, 2014; T'Sjoen, Van Caenegem, \& Wierckx, 2013).

\section{The special case of trans patients?}

There is, of course, no physiological test for gender dysphoria and the literature is fairly unequivocal in suggesting that only trans people who are indeed trans-sexual benefit from genital surgeries (Gijs \& Brewaeys, 2007). Unfortunately there are several types of presentation which may appear to be trans-sexualism at first glance but which, upon further investigation, prove not to be so. These include some forms of psychosis, people with a sexual motivation for transitioning and those people who are running from a painful reality into a more comfortable fantasy. Such presentations may overlap with issues such as chronic scrotal pain and DUB, but are, perhaps, more peculiar to people presenting to trans services. It might be argued, therefore, that trans patients specifically should have two signatures for genital surgery as a safeguard against such presentations being thought to be trans-sexualism by a single practitioner. However, we argue that a robust ongoing supportive assessment within a multidisciplinary/interdisciplinary team, including sufficient documented time living in role, would obviate the need for two signatures as a matter of general application in most cases. Of course, in those cases in which a clinician is unsure of the diagnosis, or likely prognosis, we would recommend referral for a second opinion in line with all non-trans specific interventions.

\section{The risk of the lone practitioner}

One argument against single signature referrals for genital surgeries outside of the multidisciplinary team is that of the risk of being a lone practitioner. Indeed, although not explicitly stated in the SoC, it appears the requirement for two written opinions to proceed to genital surgeries is a consequence of the increased scrutiny imposed on clinical practice by professional regulatory bodies and we might imagine the risk of the lone practitioner forms a significant part of that concern. In the United Kingdom, for instance, the Shipman inquiry was set up to investigate the murder of patients carried out by Harold Shipman, who worked as a single-handed GP (general practitioner, also known as family physician), with the main aim of the inquiry being to protect future patients from any harm (Department of Health [DoH], 2004). Subsequently, many recommendations were made by the General Medical Council (GMC), an organisation which regulates medical practice and is set up to protect, promote and maintain the health and safety of the public by ensuring proper standards in the practice of medicine (GMC, 2013).

The findings of the Shipman inquiry included recommendations to doctors working in isolation as lone practitioners that they should ensure that appropriate professional networks are in place to facilitate consultation with colleagues and ensure regular performance review is undertaken (GMC, 2006a, 2006b).

Within the field of trans health care, in 2007, lone practitioner Dr Russell Reid of London, United Kingdom, a specialist in gender dysphoria, was found guilty of serious professional misconduct. The main allegations concerned his failure to adhere to the WPATH SoC, which might be argued that it could have acted as de facto collegiate standards. He had prescribed hormone treatment at a first appointment before a diagnosis of trans-sexualism (WHO, 1992) had been made, and had also referred a patient for GRS without obtaining a second written psychiatric opinion (Dyer, 2007). The GMC's fitness to practise panel-imposed stringent conditions on Dr Reid should he choose to return to 
clinical practice wherein he was no longer allowed to undertake clinical practice in the area of gender dysphoria except within the National Health Service or in a hospital with a clinical governance ${ }^{7}$ structure acceptable to the GMC (GMC, 2007). Dr Richard Curtis, who took over Dr Reid's private practice, is now facing similar charges before the GMC's fitness to practise panel (Batty, 2013). The message is clear: working with colleagues in all areas of medicine, psychology, psychiatry, etc., is a good practice and in trans health care is deemed to be imperative. What this does not necessarily show, however, is the necessity of the two-signature system as safeguards may be put in place through clinical governance and multidisciplinary working which would mitigate the difficulties cited above but would not create possibly undue burdens on patients.

\section{Paternalism and patient centred care}

As seen above, medical regulatory bodies such as the GMC judge harshly those who do not consider such SoC seriously enough. Indeed, adherence to existing SoC in any particular field, independent of whether these SoC are necessarily logical (or indeed fair), is imperative for clinical practitioners. In the context of trans health care, SoC may be said to appear to perpetuate an attitude of paternalism towards trans patients through considering that trans people should not, or cannot, take responsibility for their own, potentially highly damaging, decisions. Perhaps this is in part because in several cases, trans people have indeed not taken this type of responsibility as they have litigated against clinicians who have provided them with treatments they have previously sought and have later come to regret. The ethical question then is as to whether, or to what extent, clinicians have a responsibility to save people who have capacity to consent from themselves. In other areas of medicine, this "saving patients from themselves" is deemed no longer appropriate and is being replaced by the culture of patient-centred medicine $(\mathrm{DoH}, 2004$; Little et al., 2001; Stewart, 2001). Indeed, in the example above, Dr Reid was reprimanded by the GMC for not adhering to WPATH SoC, not because he was considered to be a bad doctor, on the contrary. In fact, the GMC panel stated ".... it would [not] be in the public interest to deprive the community of an experienced and otherwise well respected doctor..." (GMC, 2007). The GMC did not pass judgment on the paternalism implied by a requirement for two written opinions for SRS in WPATH SoC, but on Dr Reid's non-adherence to WPATH SoC in this respect.

Every day doctors working in private practice and in national health services carry out irreversible procedures which may include the removal of healthy tissue or the loss of reproductive capacity. Not all doctors necessarily work within a team, although they will have to abide by the principles and values upon which good practice is founded which will include working within a formal framework of colleagues (GMC, 2013). They are consequently required to adhere to clinical governance processes, such as continuous professional development and audit to maintain their license to practice, and may or may not consult with a colleague regarding an irreversible intervention, although clinicians should always seek to make a clinical decision together with the patient (O'Neill, 2002). In this process, doctors are required to properly inform a patient regarding the proposed intervention, ensure that a patient makes a voluntary decision, and ensure that a patient is competent to make an informed decision (GMC, 2006b) and consequently clinicians respect the patient's autonomy to make a decision regarding any clinical intervention the patient may or may not wish to undergo. Even if non-intervention leads to the death of the patient, the patient's wish is still respected in certain cases (Gillon, 2000). 
This perhaps seems at odds with the two written opinions rule for genital surgeries for trans people. Of particular pertinence, however, is the requirement for informed consent. It might reasonably be argued that, in the case of trans people, informed consent can only be obtained when a person has been living in a role which is congruent with their sense of gender, and has fully considered the matter before them. Thus, the matter of signatures may become subsumed within a requirement for adequate preparation and assessment, rather than the crude safety measure of two signatures. We are consequently concerned that the requirement for two signatures for genital surgeries in such cases could reflect medical/psychological paternalism and potentially breaches the autonomy rights of transsexual patients through failing to consider them to be moral equals and treating them instead as less-than-independent determiners of their own good.

\section{The value of two professional opinions}

From a medical and/or psychological point of view, however, seeking two independent professional opinions regarding interventions can be advantageous (GMC, 2013; Royal College of Psychiatrists, 2009) as there can be benefits for the patient (Barqawi et al., 2011; Hahm, Niemann, Lucas, \& Frankel, 2001; Lehnhardt et al., 2008; Nirodi, Mitchell, $\&$ Mindham, 2003). For example, two independent professionals are less likely to make an erroneous decision about a patient's eligibility for genital surgeries than one, and two different clinicians may have different consultation styles where some will be better communicators than others and patients will disclose information more readily to them. Indeed, patients may withhold vital information or omit pertinent matters that might become apparent when two clinicians are involved and inconsistencies in the patient's narrative emerge (Lev, 2009). In some instances, a single clinician may be uncomfortable with the pressure exerted upon them by particular patients to give a positive recommendation to proceed with genital surgeries or other interventions. In such cases, a second opinion might be important in trying to establish what is in the patient's best interest. Furthermore, two professional opinions may give a patient greater confidence that their decision to undergo genital surgery is appropriate. However, all of these things can be carried out as part of the general work of a multidisciplinary team without the necessity for two discrete opinions at the point of referral.

Indeed, all of the aforementioned are likely to be true in all cases where two professional opinions are given, whether medical or otherwise, and whether concerning transsexualism or otherwise. One of the difficulties with the justification of the requirement for two independent professional opinions in the context of the SoC for trans people considered here is that it appears to assume that the advantages of a second opinion in some cases renders it necessary in all cases, moving from the particular to the general without justification.

There may indeed be unusually complex or difficult cases where there is a clear clinical need for further inquiry, exploration or opinion. In such cases, it is considered good practice to request a second professional opinion (Royal College of Psychiatrists, 2009). However, that would not justify a rule of general or universal application and it applies equally to all areas of medical and/or psychological practice.

\section{The inconsistency of reasoning regarding the requirement for two written opinions}

The treatment approaches for gender dysphoria in $\mathrm{SoC}$ follow the ethos of reversible interventions before the irreversible, and implementation of continuous living in the 
desired gender role prior to eligibility for genital surgeries (Coleman et al., 2012; Davies et al., 2013; Wylie et al., 2014) and the commencement of hormone treatment usually precedes these genital surgeries. Returning to our example above of a trans woman who wishes to undergo a bilateral orchidectomy as part of sex reassignment - a bilateral orchidectomy with two written psychiatric opinions may be available after commencement of feminisation with hormone treatment, which might be commenced with one written opinion only (Ahmad et al., 2013; Coleman et al., 2012; Wylie et al., 2014) notwithstanding that some changes effected by hormones are irreversible (Gooren, 2011; Spack, 2013; Wierckx et al., 2012), albeit of a potentially less significant nature than those instigated by surgery. A similar argument can, of course, be made for trans men who may receive masculinising hormone therapy following one opinion, but require two opinions for a hysterectomy. The question then becomes whether the degree of difference in the irreversible changes effected by the two interventions (hormones and surgery) is significant enough to warrant the necessity of a second opinion in the latter case, especially, given the principles of the SoC, which claim to promote autonomy and choice.

\section{Conclusion}

The requirement for two written professional opinions for genital surgeries in the $\mathrm{SoC}$ is normally referred to as a gold standard to which specialists in gender dysphoria must adhere. The rationale for the two written qualified mental health professional opinions rule concerns the prevention of harm to the trans patient, whilst, at the same time, a nontrans patient is able to access genital surgery without any written qualified mental health professional opinion. This suggests a difference in treatment between trans and non-trans patients. Moreover, the fact that some trans persons, or persons presenting as trans, may be on close examination, discovered to have other difficulties making genital surgeries inappropriate at a particular time (or at all) does not mean that this will be so for all trans people. Applying the two written qualified mental health professionals opinion rule to all trans people, rather than those for whom it is clinically indicated, appears to be disproportionately prejudicial where the impact is delay, obstruction and differential treatment (Fellmeth, 2011; Hale, 2007). Indeed, the agency of trans people should be at the centre of trans health care (Lindemann, 2012; Whittle, Turner, \& Al-Alami, 2007). Note we are not arguing for an "anything goes" approach - rather that, when undertaken within a multidisciplinary/interdisciplinary team, it is possible to provide a robust assessment and ongoing support to stable trans people such that the two-signature approval system is not necessary. This is because it would not be commensurate with the clinical need, does not afford equality of ethical practice with similar interventions, and would therefore be inappropriate. Of course, as we have seen, it will not be possible for clinicians to simply change their practice to a single signature for genital surgery without putting themselves at significant risk of censure and litigation and we therefore call upon lawmakers, and the revisers of the SoC, as well as the relevant governing bodies and professional organisations to endorse such changes of practice in order for clinicians to more ethically work with trans patients towards a patient-centred care which holds patient choice (and responsibility for that choice) as well as that of the clinician to be key.

\section{Notes}

1. Trans men are people assigned female at birth but who identify as men.

2. Trans women are people assigned male at birth but who identify as women. 
3. A cisgender person is a person who is content to remain the gender they were assigned at birth.

4. Of course, not every person with gender dysphoria seeks GRS and it is not necessarily the proper end of a given gender dysphoric person's journey.

5. This is notably lower at around $0.025 \%$ within the Charing Cross Gender Clinic within the United Kingdom National Health Service which has stringent criteria for referral.

6. A cisgender person is a person who is content to remain the gender they were assigned at birth.

7. The main mechanism by which the duty to provide care of an acceptable quality is fulfilled is known as clinical governance.

\section{References}

Ahmad, S., Barrett, J., Beaini, A., Bouman, W.P., Davies, A., Greener, H.M., ... Stradins, L. (2013). Gender dysphoria services: A guide for general practitioners and other healthcare staff. Sexual and Relationship Therapy, 28(3), 172-185.

American Psychiatric Association (2013). Diagnostic and statistical manual of mental disorders (5th ed.). Washington, DC: Author.

Barqawi, A.B., Turcanu, R., Gamito, E.J., Lucia, S.M., O’Donnell, C.I., Crawford, E.D., ... La Rosa, F.G. (2011). The value of second-opinion pathology diagnoses on prostate biopsies from patients referred for management of prostate cancer. International Journal of Clinical and Experimental Pathology, 4(5), 468-475.

Barrett, J. (Ed.). (2007). Transsexual and other disorders of gender identity. Oxford: Radcliffe Publishing.

Batty, D. (2013, January 6). Doctor under fire for alleged errors prescribing sex-change hormones. The Guardian. Retrieved September 1, 2013, from http://www.theguardian.com/society/2013/ jan/06/transexualism-gender-reassignment-richard-curtis

Beauchamp, T.L., \& Childress, J.F. (2009). Principles of biomedical ethics (6th ed.). Oxford: Oxford University Press.

Bouman, W.P., \& Richards, C. (2013). Diagnostic and treatment issues for people with gender dysphoria. Sexual and Relationship Therapy, 28(3), 165-171.

Cairns, R., Maddock, C., Buchanan, A., David, A.S., Hayward, P., Richardson, G., ... Hotopf, M. (2005). Prevalence and predictors of mental incapacity in psychiatric in-patients. British Journal of Psychiatry, 187, 379-385.

Centre for Evidence Based Medicine (CEBM). (2013). Levels of evidence. Retrieved October 14, 2013, from http://www.cebm.net/?o=1025

Cole, C.M., O’Boyle, M., Emory, L.E., \& Meyer III, W.J. (1997). Comorbidity of gender dysphoria and other major psychiatric diagnoses. Archives of Sexual Behavior, 26 (1), 13-26.

Coleman, E., Bockting, W., Botzer, M., Cohen-Kettenis, P., DeCuypere, G., Feldman, J., ... Zucker, K. (2012). Standards of care for the health of transsexual, transgender, and gender-nonconforming people, version 7. International Journal of Transgenderism, 13(4), 165-232.

Colizzi, M., Costa, R., \& Todarello, O. (2014). Transsexual patients' psychiatric comorbidity and positive effect of cross-sex hormonal treatment on mental health: Results from a longitudinal study. Psychoneuroendocrinology, 39(1), 65-73.

Cresswell, J., Murphy, G., \& Hodge, S. (2012). The ECT Accreditation Service (ECTAS). Standards for the administration of ECT (10th ed.). London: Royal College of Psychiatrists.

Davies, A., Bouman, W.P., Richards, C., Barrett, J., Ahmad, A., Baker, K., ... Stradins, L. (2013). Patient satisfaction with gender identity clinic services in the United Kingdom. Sexual and Relationship Therapy, 28(4), 400-418.

De Cuypere, G., T'Sjoen, G., Beerten, R., Selvaggi, G., De Sutter, P., Hoebeke, P., . . Rubens, R. (2005). Sexual and physical health after sex reassignment surgery. Archives of Sexual Behavior, $34(6), 679-690$.

Department of Health (DoH). (2004). Fifth report - safeguarding patients: Lessons from the past proposals for the future, command paper Cm 6394. London: Author.

Di Santo, M., Tarozzi, N., Nadalini, M., \& Borini, A. (2012). Human sperm cryopreservation: Update on techniques, effect on DNA integrity, and implications for ART. Advances in Urology, 2012.

Drescher, J. (2010). Queer diagnoses: Parallels and contrasts in the history of homosexuality, gender variance, and the Diagnostic and Statistical Manual (DSM). Archives of Sexual Behavior, 39, $427-460$. 
Dyer, O. (2007) Gender disorder specialist is found guilty of serious professional misconduct. British Medical Journal, 334, 1134.

Edozien, L.C. (2006) Hysterectomy for benign conditions. British Medical Journal, 330, $1457-1458$.

Ettner, R., Monstrey, S., \& Eyler, A.E. (Eds.). (2007). Principles of transgender medicine and surgery. New York, NY: The Haworth Press.

Farquhar, C.M., Harvey, S.A., Yu, Y., Sadler, L., \& Stewart, A.W. (2006). A prospective study of 3 years of outcomes after hysterectomy with and without oophorectomy. American Journal of Obstetrics and Gynecology, 194, 711-717.

Fellmeth, A.X. (2011). Choice of gender identity in international human rights law. In M.H. Arsanjani, J.K. Cogan, R.D. Sloane, \& S. Wiessner (Eds.), Looking to the future: Essays on international law in honor of W. Michael Reisman (pp. 499-515). Boston, MA: Martinus Nijhoff.

General Medical Council (GMC). (2006a). Good medical practice in cosmetic surgery/procedures. London: Author.

General Medical Council (GMC). (2006b). Seeking patients' consent: The ethical considerations. London: Author.

General Medical Council (GMC). (2007). Fitness to practise panel hearing. Retrieved September 1, 2013 from http://image.guardian.co.uk/sys-files/Guardian/documents/2007/05/25/reid.PDF

General Medical Council (GMC). (2013). Good medical practice. London: Author.

Gijs, L., \& Brewaeys, A. (2007). Surgical treatment of gender dysphoria in adults and adolescents: Recent developments, effectiveness, and challenges. Annual Review of Sex Research, 18, $178-224$.

Gillon, R. (2000). Refusal of potentially life-saving blood transfusions by Jehovah's Witnesses: Should doctors explain that not all JWs think it's religiously required? Journal of Medical Ethics, 26, 299-301.

Gooren, L.J. (2011). Care of transsexual persons. New England Journal of Medicine, 364, $1251-1257$.

Hahm, G.K., Niemann, T.H., Lucas, J.G., \& Frankel, W.L. (2001). The value of second opinion in gastrointestinal and liver pathology. Archives of Pathology \& Laboratory Medicine, 125(6), $736-739$.

Hale, C.J. (2007). Ethical problems with the mental health evaluation standards of care for adult gender variant prospective patients. Perspectives in Biology and Medicine, 50(4), $491-505$.

Haraldsen, I.R., \& Dahl, A.A. (2000). Symptom profiles of gender dysphoric patients of transsexual type compared to patients with personality disorders and healthy adults. Acta Psychiatrica Scandinavica, 102(4), 276-281.

Hill, D.B., Rozanski, C., Carfagnini, J., \& Willoughby, B. (2005). Gender identity disorders in childhood and adolescence: A critical inquiry. In D. Karasic \& J. Drescher (Eds.), Sexual and gender diagnoses of the diagnostic and statistical manual (DSM) (pp. 7-34). New York, NY: The Haworth Press.

Hoshiai, M., Matsumoto, Y., Sato, T., Ohnishi, M., Okabe, N., Kishimoto, Y., ... Kuroda, S. (2010). Psychiatric comorbidity among patients with gender identity disorder. Psychiatry and Clinical Neurosciences, 64, 514-519.

Keoghane, S.R., \& Sullivan, M.E. (2010). Investigating and managing chronic scrotal pain. British Medical Journal, 341, 1263-1266.

Kersting, A., Reutemann, M., Gast, U., Ohrmann, P., Suslow, T., Michael, N., \& Arolt V. (2003). Dissociative disorders and traumatic childhood experiences in transsexuals. Journal of Nervous and Mental Disease, 191(3), 182-189.

Klein, C., \& Gorzalka, B.B. (2009). Sexual functioning in transsexuals following hormone therapy and genital surgery: A review. The Journal of Sexual Medicine, 6(11), 2922-2939.

Landén, M., Wålinder, J., Hambert, G., \& Lundström, B. (1998). Factors predictive of regret in sex reassignment. Acta Psychiatrica Scandinavica, 97, 284-289.

Lawrence, A.A. (2003). Factors associated with satisfaction or regret following male-to-female sex reassignment surgery. Archives of Sexual Behavior, 32(4), 299-315.

Lehnhardt, M., Daigeler, A., Hauser, J., Puls, A., Somaru, C., Kuhnen, C., \& Steinau, H.U. (2008). The value of expert second opinion in diagnosis of soft tissue sarcomas. Journal of Surgical Oncology, 97(1), 40-43. 
Leslie, T.A., Illing, R.O., Cranston, D.W., \& Guillebaud, J. (2007). The incidence of chronic scrotal pain after vasectomy: A prospective audit. British Journal of Urology International, 100(6), $1330-1333$

Lev, A.I. (2009). The ten tasks of the mental health provider: Recommendations for revision of the World Professional Association for Transgender Health's Standards of Care. International Journal of Transgenderism, 11(2), 74-99.

Lindemann, N.J. (2012). Still quiet after all these years. Bioethical Inquiry, 9, 249-259.

Little, P., Everitt, H., Williamson, I., Warner, G., Moore, M., Gould, C., ... Payne, S. (2001). Preferences of patients for patient centred approach to consultation in primary care: Observational study. British Medical Journal, 322, 468-472.

Loutradi, K.E., Kolibianakis, E.M., Venetis, C.A., Papanikolaou, E.G., Pados, G., Bontis, I., \& Tarlatzis, B.C. (2008). Cryopreservation of human embryos by vitrification or slow freezing: A systematic review and meta-analysis. Fertility and Sterility, 90(1), 186-193.

Meyer-Bahlburg, H.F. (2010). From mental disorder to iatrogenic hypogonadism: Dilemmas in conceptualizing gender identity variants as psychiatric conditions. Archives Sexual Behavior, 39, $461-476$.

Michel, A., Ansseau, M., Legros, J.J., Pitchot, W., \& Mormont, C. (2002). The transsexual: What about the future? European Journal of Psychiatry, 17, 353-362.

Murad, M.H., Elamin, M.B., Garcia, M.Z., Mullan, R.J., Murad, A., Erwin, P.J., \& Montori, V.M. (2010). Hormonal therapy and sex reassignment: A systematic review and meta-analysis of quality of life and psychosocial outcomes. Clinical Endocrinology, 72(2), 214-231.

Nieder, T.O., Briken, P., \& Richter-Appelt, H. (2013). Transgender, transsexualität und geschlechtsdysphorie: Aktuelle entwicklungen in diagnostik und therapie [Transgender, transsexualism and gender dysphoria: Current developments in assessment and care]. Psych Up2Date, 7 (6), 373-388.

NHS Audit, Information \& Analysis Unit. (2008). Survey of patient satisfaction with transgender services. London: Department of Health.

Nirodi, P., Mitchell, A.J. \& Mindham, R.H.S. (2003). Survey of expert second opinions in a tertiary psychiatric out-patient clinic in the Yorkshire region between 1988 and 2000. Psychiatric Bulletin, 27, 416-420.

O'Neill, O. (2002). Autonomy and trust in bioethics. Cambridge: Cambridge University Press.

Phipps, W.R. (2007). Dysfunctional uterine bleeding. In V. Lewis (Ed.), Reproductive endocrinology and infertility (pp. 36-45). Austin, TX: Landes Bioscience.

Richards, C., \& Seal, L. (2014). Trans people's reproductive options and outcomes. Journal of Family Planning and Reproductive Health Care. doi:10.1136/jfprhc-2013-100669.

Royal College of Psychiatrists. (2009). Good psychiatric practice, college report CR154 (3rd ed.). Dorchester: The Dorset Press.

Simon, L., Zsolt, U., Fogd, D., \& Czobor, P. (2011). Dysfunctional core beliefs, perceived parenting behavior and psychopathology in gender identity disorder: A comparison of male-to-female, female-to-male transsexual and nontranssexual control subjects. Journal of Behavior Therapy and Experimental Psychiatry, 42(1), 38-45.

Smith, Y.L.S., Van Goozen, S.H.M., Kuiper, A.J., \& Cohen-Kettenis, P.T. (2005). Sex reassignment: Outcomes and predictors of treatment for adolescents and adult transsexuals. Psychological Medicine, 35, 89-99.

Spack, N.P. (2013). Management of transgenderism. Journal of the American Medical Association, 309(5), 478-484.

Stewart, M. (2001). Towards a global definition of patient centre care. British Medical Journal, 322, 444-445.

T'Sjoen, G., Van Caenegem, E., \& Wierckx, K. (2013). Transgenderism and reproduction. Current Opinion in Endocrinology, Diabetes and Obesity, 20, 575-579.

Veatch, R. (2003). The basics of bioethics (2nd ed.). Upper Saddle River, NJ: Pearson Educational Incorporation.

Walker, P.A., Berger, J.C., Green, R., Laub, D.R., Reynolds, C.L., \& Wollman, L. (1985). Standards of care: The hormonal and surgical sex reassignment of gender dysphoric persons. Archives of Sexual Behavior, 14(1), 79-90.

Whittle, S., Turner, L., \& Al-Alami, M. (2007). Engendered penalties: Transgender and transsexual people's experiences of inequality and discrimination. Wetherby: Communities and Local Government Publications. 
Wierckx, K., Mueller, S., Weyers, S., Van Caenegem, E., Roef, G., Heylens, G., \& T'Sjoen G. (2012). Long-term evaluation of cross-sex hormone treatment in transsexual persons. Journal of Sexual Medicine, 9(10), 2641-2651.

World Health Organization (WHO). (1992). International classification of diseases (10th ed.). Geneva: Author.

Wylie, K.R., Barrett, J., Besser, M., Bouman, W.P., Bridgeman, M., Clayton, A., ... Ward, D. (2014). Good practice guidelines for the assessment and treatment of adults with gender dysphoria. Sexual and Relationship Therapy, 29(2), 154-214. 